\title{
Spherical wave rotation in spherical near-field antenna measurements
}

\section{Wu, Jian; Larsen, Flemming Holm; Lemanczyk, J.}

Published in:

Antennas and Propagation Society International Symposium

Link to article, DOI:

10.1109/APS.1991.175128

Publication date:

1991

Link back to DTU Orbit

Citation (APA):

Wu, J., Larsen, F. H., \& Lemanczyk, J. (1991). Spherical wave rotation in spherical near-field antenna measurements. In Antennas and Propagation Society International Symposium (Vol. Volume 3, pp. 1470-1473). IEEE. https://doi.org/10.1109/APS.1991.175128

\section{General rights}

Copyright and moral rights for the publications made accessible in the public portal are retained by the authors and/or other copyright owners and it is a condition of accessing publications that users recognise and abide by the legal requirements associated with these rights.

- Users may download and print one copy of any publication from the public portal for the purpose of private study or research.

- You may not further distribute the material or use it for any profit-making activity or commercial gain

- You may freely distribute the URL identifying the publication in the public portal

If you believe that this document breaches copyright please contact us providing details, and we will remove access to the work immediately and investigate your claim 


\title{
SPHERICAL WAVE ROTATION IN SPHERICAL NEAR-FIELD ANTENNA MEASUREMENTS
}

\author{
J. Wu, F. Holm Larsen, J. Lemanczyk \\ Technical University of Denmark
}

Building 348, EMI, DK-2800, Lyngby, Denmark

\begin{abstract}
The rotation of spherical waves in spherical near-field antenna measurement is discussed. Considering the many difficult but interesting features of the rotation coefficients, an efficient rotation scheme is derived. The presented example shows the feasibility of the new method.
\end{abstract}

\section{Introduction}

In spherical near-field antenna measurements, there are often cases where the measured antenna cannot be mounted precisely in the user's own coordinate system; the measured patterns will be given in the measurement coordinate system only. The difficulty is then to present the measured patterns, such as cuts through the main beam boresight and contour plots in the user's coordinate system.

Therefore, to rotate the spherical waves of the original measurement from the measurement coordinate system to a user defined coordinate system would be very desirable because it is more accurate than the interpolation methods.

\section{Spherical Wave Rotation}

The rotation of the spherical waves can be described by three Euler angles $\left(\phi_{0}, \theta_{0}, \chi_{0}\right)$ as show in Fig.1 [1]. The first and the third angles represent the rotation about the $z$-axis of the coordinate system. These cause only a phase shift of each spherical wave. The second angle is a rotation about the $y$-axis where a set of rotation coefficients is needed. The complete relation between the original spherical waves and the ones after rotation is given by

(c)

$$
\mathbf{n}
$$

$$
\mathbf{n}
$$

$F_{s m n}(r, \theta, \psi)=\Sigma e^{i m \phi_{0}} d_{\mu m}\left(\theta_{0}\right) e^{i \mu \chi_{0}} F_{s \mu n}\left(r^{\prime}, \theta^{\prime}, \psi^{\prime}\right)$.

$$
\mu=-n
$$

\section{Rotation Coefficients}

It is seen from (1) that the rotation coefficient $d$ is the key parameter to be calculated in order to rotate the spherical waves. The complete set of d's forms a pyramidal structure made up of layers of $2 n \times 2 n$ square matrices, with each layer having certain symmetry properties, for each $n$ index, Wacker [2]. However the pyramid can be calculated layer by layer. For each layer, the rotation coefficients can be obtained either directly from an expansion of $\theta_{0}$ or by using a three term recurrence formula [3] 


$$
\begin{gathered}
\sqrt{\sqrt{(n+m+1)(n-m)}} \sin \theta_{0} d_{\mu, m+1}^{n}\left(\theta_{0}\right) \\
+\sqrt{(n+m)(n-m+1)} \sin \theta_{0} d_{\mu, m-1}\left(\theta_{0}\right)=\left(2 \mu-2 m \cos \theta_{0}\right) d_{\mu, m}\left(\theta_{0}\right)
\end{gathered}
$$

together with some special case formulas as starting points [1]. The second procedure is more efficient compared with the first and it has been carried out for general $\theta_{0}$ and low mode cases. The study shows that for the $\theta_{0}=90^{\circ}$ case, the significant rotation coefficients in each layer form a circle, see Fig.2. When $\theta_{0}$ becomes less than $90^{\circ}$, the circle deforms into an ellipse, see Fig. 3 and eventually collapses into a straight line along the diagonal for the $\theta_{0}=0^{\circ}$ case, see Fig.4. The study also shows that outside the ellipse for general $\theta_{0}$, the coefficients decay to such an extent that they give underflow in the computer. The recurrence formula cannot be performed with two zero initial values. Another difficulty is that the recursion can be performed only in the direction of going inwards of the ellipse. It will give wrong values going outwards of the ellipse.

\section{Calculation Scheme}

A new calculation scheme has been found to overcome the above mentioned difficulties. The main feature of the scheme is to ignore the calculation of the very small coefficients outside the ellipse. Therefore, not only will the underflow problem be eliminated but much computation time will be saved as well especially for small rotations in $\theta_{0}$. The recursion is started somewhere on both sides outside the ellipse, see Fig.5, with 0 and a small number and meet at a point in the middle of the ellipse where the exact value is calculated by two other special recursions for calibrating the whole row of data. As Fig. 5 shows, part of the exact coefficients used for calibration are specially obtained from a recursion which is similar to (2) but along the $\mu$-axis and started from the point where the ellipse of significant values cuts the edge of the $\mu$-m square and go inwards till the diagonal or major axis of the ellipse. The rest of the exact coefficients used for calibration are obtained from a newly derived recurrence formula along the diagonal of

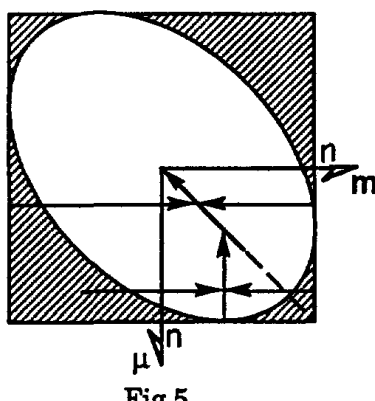

Fig.5 the $\mu-m$ square 


$$
\begin{aligned}
& \frac{n(n+1)-k(k+1)}{2 k+1}\left(1+\cos ^{2} \theta_{0}\right) d_{k+1, k+1}\left(\theta_{0}\right)+\frac{n(n+1)-k(k-1)}{2 k-1}\left(1+\cos ^{2} \theta_{0}\right) d_{k-1, k-1}\left(\theta_{0}\right) \\
& =\left[\frac{2 n(n+1)-2 k^{2}+1}{4 k^{2}-1}\left(1+\cos ^{2} \theta_{0}\right)-\sin ^{2} \theta_{0}\right] 2 k d_{k, k}\left(\theta_{0}\right)
\end{aligned}
$$

The derivation of (3) used a similar procedure as described by R.L. Lewis for the $\theta_{0}=90^{\circ}$ case [4]. This recursion may be started from zero and a small number and calibrated at the meeting point with the exact value obtained from last recursion. In this way, half the rotation coefficients have been obtained already. The other half can be obtained easily from the application of symmetry.

\section{Example}

One rotation example is presented here from a set of real antenna measurement data. The highest mode index is 239. The user's coordinate system is very different from the measurement coordinate system, therefore the spherical waves must be rotated after the measurement with the Euler angles equal to $\left(79.67^{\circ}, 29.16^{\circ}, 12.37^{\circ}\right)$. Contour plots before (a) and after (b) the rotation are given in Fig. 6.

\section{Conclusion}

The rotation of spherical waves for general $\theta_{0}$ has been realized by the new method. This additional possibility makes the spherical near-field antenna measurement technique becomes more flexible. With this rotation possibility, an intercomparison between different measurement facilities can be carried out with the final results presented with the same user defined coordinate system. Finally, it should be noted that the computation of spherical wave rotation coefficients is also relevant in atomic physics [3] and solution of scattering problems by the T-matrix method[5].

References:

[1] J. E. Hansen, "Spherical near-field antenna measurements", Peter Peregrinus Ltd, London 1988.

[2] P. F. Wacker, "Non-planar near-field measurements: Spherical scanning", Report NBSIR 75-809, Electromagnetics Division, National Bureau of Standards, Boulder, Colorado, June 1975.

[3] A. R. Edmonds,"Angular momentum in quantum mechanics", 2nd edition, Princeton University Press, New Jersey, 1974.

[4] R. L. Lewis, " The use of three term recursion relations for numerical computations as applied to near-field spherical scanning" Proceedings of URSI Symposium on Electromagnetic Wave Theory, Stanford, California, 1977. pp.224-226

[5] B. Peterson and S. Ström, "T matrix for electromagnetic scattering from an arbitrary number of scatterers and representation of E(3)", Physical Review D, Vol. 8,pp. 3661-3678, November 1973. 


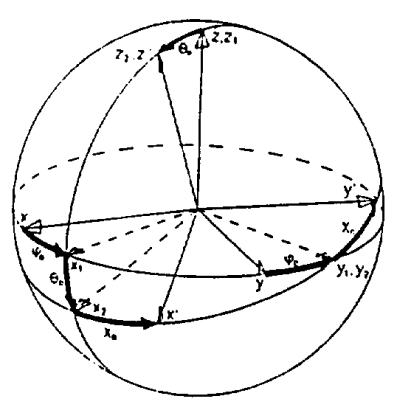

Fig.1

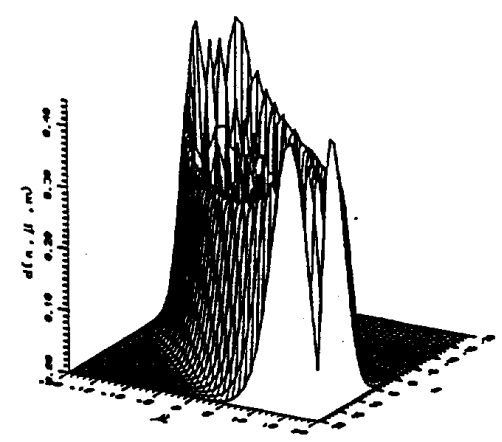

Fig.3

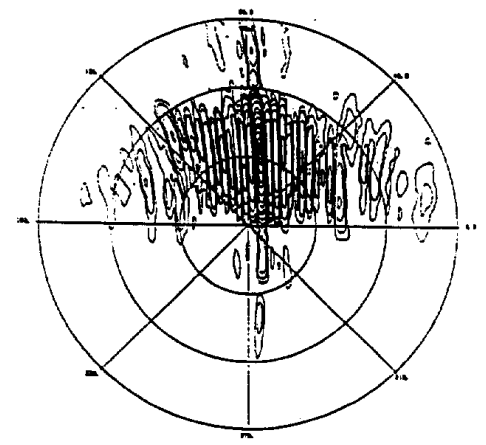

(a)

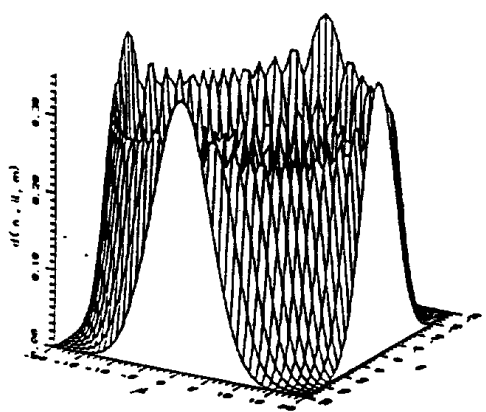

Fig.2

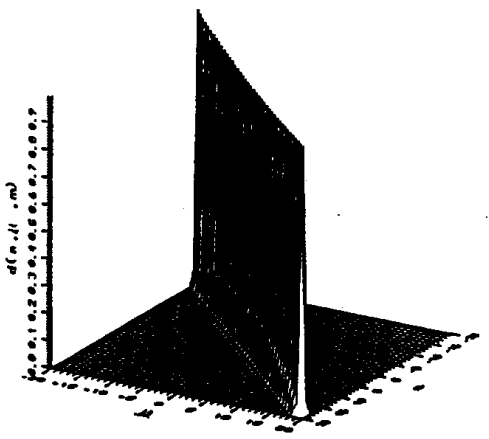

Fig.4

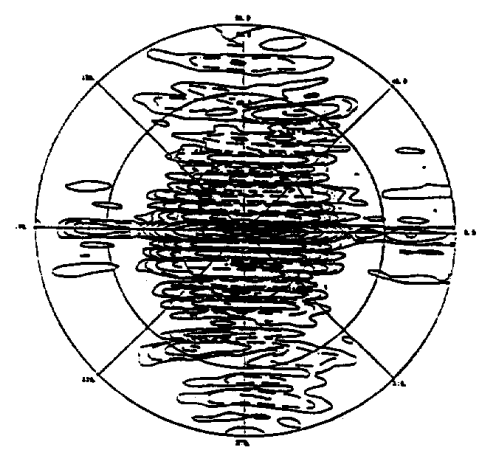

(b)

Fig.6 